\title{
Artigos
}

\section{(In)Visibilidade do usuário-trabalhador na interação com profissionais de saúde no contexto de uma Unidade de Saúde da Família}

(In)visibility of service user-workers in the interaction with health care professionals in the context of a family health center (abstract: p. 18)

(In)Visibilidad del usuario-trabajador en la interacción con profesionales de salud en el contexto de una unidad de salud de la familia (resumen: p. 18)

Andréa Garboggini Melo Andrade ${ }^{(a)}$

<andrea.andrade@saude.ba.gov.br> iD

Robson da Fonseca Neves ${ }^{(b)}$

<robsonfisioba@gmail.com>

Rita de Cássia Peralta Carvalho(c)

<ritadecassia.carvalho@saude.ba.gov.br>

Elizabeth Costa Dias ${ }^{(\mathrm{d})}$

<bethdias@gmail.com>

Mônica Angelim Gomes de Lima ${ }^{(\mathrm{e})}$

<angelim@ufba.br>

\author{
(a,c) Centro Estadual de \\ Referência em Saúde do \\ Trabalhador, Diretoria de \\ Vigilância e Atenção à Saúde \\ do Trabalhador, Secretaria de \\ Saúde do Estado da Bahia. \\ Rua Pedro Lessa, 123, Canela. \\ Salvador, BA, Brasil. 40110-050. \\ (b) Departamento de Fisioterapia, \\ Programa de Pós-Graduação \\ em Fisioterapia, Universidade \\ Federal da Paraíba. João \\ Pessoa, PB, Brasil. \\ (d) Faculdade de Medicina, \\ Universidade Federal de \\ Minas Gerais. Belo Horizonte, \\ MG, Brasil.
}

continua pág. 15

Buscou-se compreender como demandas de saúde relacionadas ao trabalho aparecem na interação usuário (trabalhador) - profissionais de Saúde da Família e repercutem sobre o cuidado. Adotou-se a perspectiva etnográfica para produção de dados com registro em diário de campo dos atendimentos observados, entrevistas situadas e semiestruturadas. 0 trabalhador tornou-se visível para os profissionais por meio de pedidos formais, manifestações clínicas, vínculo estabelecido e perfil do usuário. Nos atendimentos foram observadas respostas orientadas pela queixa clínica e lacunas na coordenação do cuidado. A (in)visibilidade do trabalhador no contexto dos atendimentos apareceu articulada e em camadas, abrangendo aspectos do indivíduo, processo de trabalho e da proteção social. Compreender essas sobreposições no cuidado aos trabalhadores na Atenção Primária pode contribuir para qualificar e ampliar a resolutividade da Atenção à Saúde no Sistema Público de Saúde.

Palavras-chave: Trabalhador. Saúde do trabalhador. Atenção Primária à Saúde. Integralidade em saúde. Pesquisa qualitativa. 


\section{Introdução}

O reconhecimento do trabalho e do usuário-trabalhador ${ }^{(f)}$ pelos profissionais das equipes da Atenção Primária à Saúde (APS) é fundamental para a implementação das ações de saúde do trabalhador na Rede de Atenção à Saúde (RAS) do Sistema Único de Saúde (SUS) ${ }^{1,2}$. Essas ações são orientadas pela Política Nacional de Saúde do Trabalhador e da Trabalhadora (PNSTT), que reconhece a APS como componente central dessa rede para produção do cuidado integral e resolutivo, por meio de informações sobre atividades produtivas, do perfil da população trabalhadora do território e suas necessidades de saúde ${ }^{1,2}$.

A integralidade da atenção incorpora a compreensão ampliada de saúde e requer qualificação dos profissionais para o adequado reconhecimento da relação das condições de vida e saúde-doença-trabalho, e, consequentemente, realização de ações de promoção e proteção da saúde, prevenção de doenças, vigilância, assistência e reabilitação, incluindo orientaçôes e encaminhamentos trabalhistas e previdenciáros ${ }^{2}$. No território da APS é possível materializar essa integração por meio do diálogo entre os sujeitos no cotidiano das práticas, na oferta do cuidado e na organização da Atenção à Saúde mediante identificação de necessidades e demandas ${ }^{3}$.

No entanto, açốes de cuidado dos usuários-trabalhadores na APS têm sido pontuais e pouco articuladas com as diretrizes e os objetivos da PNSTT, observando-se a sobrecarga de trabalho dos profissionais, o despreparo das equipes para as questóes que envolvem as relações saúde-ambiente-trabalho e a falta de apoio institucional como principais dificuldades enfrentadas ${ }^{4}$.

Apesar das complexas relações saúde-ambiente-trabalho que se desenrolam nos territórios, estudos apontam que a "condição de trabalhador" dos usuários e o reconhecimento do trabalho como central na determinação dos processos saúde-doença permanecem invisíveis ou marginalizados ${ }^{5}$. O desenvolvimento de açôes de saúde do trabalhador no contexto da APS fica comprometido mesmo diante desse reconhecimento, em decorrência de outros desafios postos pelo processo de trabalho. Assim, as equipes não conseguem atender às demandas de saúde do usuário-trabalhador e coordenar o cuidado resolutivo ${ }^{2}$ nesse encontro clínico, com reconhecimento e ação em torno da demanda de saúde relacionada ao trabalho.

Reconhecer e dar visibilidade ao trabalho, ao usuário-trabalhador, e reforçar o papel da APS para tecer o cuidado integral na RAS ficam dificultados em um contexto político e econômico adverso, marcado por decisões que contrariam os direitos sociais constitucionais da população brasileira.

A defesa do SUS e da qualidade de vida das pessoas é essencial para o enfrentamento das mudanças impostas pela ideologia neoliberal em ascensão, que caminha na direção da retirada de direitos e desconstrução do SUS $S^{6}$, que tende a acentuar as desigualdades sociais e impedir a participação paritária dos indivíduos na vida social, reforçando as injustiças sociais ${ }^{7}$.

\author{
(f) Neste estudo, foi \\ considerado que todo adulto \\ é um potencial trabalhador. \\ Dada a abrangência \\ desse termo na PNSTT, \\ considerou-se usuário(a)- \\ trabalhador(a) todo(a) \\ usuário(a) adulto(a) (acima \\ de 18 anos) atendido(a) \\ na Unidade de Saúde da \\ Família, independentemente \\ de gênero, raça, forma \\ de inserção no mercado \\ de trabalho e vínculo \\ empregatício. Sem negar \\ a existência de crianças e \\ adolescentes trabalhando \\ no território, adotou-se \\ esse recorte de idade ao \\ concordar com a ilegalidade \\ do trabalho infantil e por \\ entender que esse é um \\ tema complexo, dotado de \\ particularidades, que requer \\ estudos específicos e mais \\ aprofundados.
}


Compreender o cotidiano de trabalho em uma Unidade de Saúde da Família (USF) em meio a um cenário adverso faz-se relevante para prosseguir com a proposta de implantação das açôes de saúde do trabalhador (ST) por meio da APS, com o envolvimento dos diversos atores que fazem parte dessa realidade. Uma estratégia para dar força ao "ponto da rede" que deve coordenar o entrelaçamento dos fios que conduzirão o usuário-trabalhador na RAS.

O objetivo deste estudo foi compreender, no contexto de uma USF, o que a interação entre profissional de saúde e usuário-trabalhador revela sobre a gestão do cuidado em saúde do trabalhador.

\section{Método}

Guiada ${ }^{(g)}$ pelo interesse sobre a interação do usuário adulto com os profissionais de saúde, aproximei-me de recursos da abordagem etnográfica, como estratégia metodológica, a fim de possibilitar a vivência do campo, articulando os diferentes sentidos e capacidades que me seriam requeridos ${ }^{8}$ para traduzir em texto a realidade observada.

Os dados qualitativos foram produzidos de abril a outubro de 2018, em uma USF do município de Salvador-BA. Na ocasião, havia cinco equipes mínimas de saúde da família (eSF), com profissionais de medicina, enfermagem, odontologia; auxiliares e agentes comunitários de saúde (ACS). Uma equipe do Núcleo Ampliado de Saúde da Família e Atenção Básica (Nasf-AB), composta por profissionais de serviço social, nutrição, psicologia, fisioterapia e de terapia ocupacional, apoiava essa e outra USF do distrito sanitário.

Recorri à observação participante como técnica principal de produção de dados e o recurso do caderno de campo para descrever cenas observadas, falas, sensações experimentadas, reflexôes e indagações. Os espaços de interação das cenas apresentadas no recorte deste manuscrito compreenderam sala de espera, de acolhimento e consultas médicas ${ }^{(\mathrm{h})}$.

Uma maneira de "dar luz" ao "como" os profissionais (não)reconhecem, (não) validam, (não)priorizam, (não)qualificam demandas de saúde de usuários-trabalhadores no contexto da USF e, assim, responder: como se dá a interação nos espaços da Unidade de Saúde da Família? Em que medida os profissionais relacionam demandas de saúde com o trabalho? O que fazem a partir daí?

Os registros realizados constituíram-se como parte da textualização dos fenômenos 9 observados no campo. A ampliação desses registros com descriçốes minuciosas das cenas observadas possibilitou-me reconhecer detalhes e sutilezas ${ }^{8}$ das interaçốes estabelecidas entre os sujeitos da pesquisa, aos quais fiz indagaçôes e reflexóes que contribuíram para reorientar as aproximaçôes e os diálogos com esses sujeitos.

As vozes dos sujeitos foram estimuladas por meio de abordagens conversacionais (no contexto da observação participante) e do recurso da entrevista situada ${ }^{8} \mathrm{e}$ da entrevista semiestruturada. As entrevistas situadas ocorreram na cena dos

\section{(g) Considerando que a produção de dados em campo foi realizada pela primeira autora desse manuscrito, optou-se por valorizar o caminho etnográfico, apresentando a trajetória metodológica e os resultados na primeira pessoa do singular.}


atendimentos, com dois profissionais de enfermagem, dois de medicina, um ACS e um técnico de enfermagem; as entrevistas semiestruturadas foram realizadas com profissionais de medicina (01), enfermagem (02), terapia ocupacional (02), fisioterapia (01), serviço social (01), ACS (03) e usuários (02) ${ }^{(i)}$.

A escolha dos entrevistados ocorreu à medida que me aproximava dos profissionais não obedecendo a critérios preestabelecidos quanto ao número e às categorias profissionais. Para isso, adotei, respectivamente, o critério da saturação empírica ${ }^{10}$ e o princípio da representatividade para garantir a participação dos distintos núcleos de saberes ${ }^{11}$ dos profissionais das equipes da USF e do Nasf-AB.

As falasiluminaram os processos explicativos e compreensivos no entorno do objeto de investigação. Interessava-me compreender as demandas de saúde apresentadas pelos usuários adultos; possível relação com o trabalho; a identificação do usuário-trabalhador pelo profissional e ações daí decorrentes.

O tratamento dos dados produzidos foi orientado pelo interesse em examinar e coproduzir, em um processo compreensivo hermenêutico, o fenômeno investigado com base na aproximação do contexto de interação social ${ }^{12}$, observando e oportunizando a fala de diferentes atores, o que ajudou a compor um enredo com as várias cenas observadas. Por meio da triangulação dos "três atos cognitivos", o olhar, o ouvir e o escrever", a maneira como as demandas de saúde do trabalhador eram percebidas e abordadas pelos profissionais de saúde da USF se delineou. Pistas interpretativas foram reveladas, guiando-me na busca por confirmação ou negação de questionamentos suscitados e hipóteses de campo.

A análise dos dados foi orientada pelas categorias: percepção profissional sobre o usuário adulto e suas demandas de saúde; circunstância para o (não)reconhecimento do usuário-trabalhador; disparadores e barreiras para o reconhecimento; o ato seguinte ao reconhecimento.

Importante acrescentar o efeito catalisador da minha presença em campo, profissional de saúde com atuação no campo da ST. Interagi e interferi no curso da produção da investigação, guiada pelo objeto de estudo, porém ampliando o processo investigativo para além do que estava previamente delimitado. Assim, intercessóes foram produzidas "como uma forma de perturbação, gerando ondas em todas as direções a partir do ponto de incisão." ${ }^{13}$ (p. 93).

A pesquisa foi aprovada por Comitê de Ética em Pesquisa (parecer consubstanciado n. 2.677.897/2018). Para garantir o anonimato dos informantes, adotei identidades profissionais seguidas por números cardinais (Profissional de: Enfermagem (ProfE); Médico (ProfM); Terapeuta Ocupacional (ProfTO); e Agente Comunitário de Saúde (ACS).

(i) Os dados das entrevistas com usuários não foram utilizados nesse recorte e serão trabalhados em outros produtos pertencentes ao projeto maior "Saúde do Trabalhador na Estratégia de Saúde da Família: compreender para agir". 


\section{Resultados e discussão}

\section{Saúde do Trabalhador na USF: compreender limites para produzir possibilidades}

A caminho da USF vi trabalho por toda parte, nas esquinas, descida de beco, por cima, embaixo e entre casas, um território repleto de atividades produtivas e trabalhadores. Homens, mulheres, crianças, idosos; negros, pardos e brancos; trabalhador braçal, informal e precarizado; instruído ou sem escolaridade; desempregados, aposentados e incapacitados.

Foi preciso olhar os profissionais da USF, exauridos para garantir, "na ponta", o que as políticas públicas preconizam, sem as condiçôes necessárias; confrontados, diariamente, com a difícil realidade dos usuários do território, com a violência e as iatrogenias dos sistemas de saúde, previdência e assistência social. Precisava reconhecê-los como trabalhadores, para então compreender "o como" e "o(s) por quê(s)" (não)reconheciam os usuários-trabalhadores atendidos.

Aos poucos, a certeza de que o usuário-trabalhador era invisível aos olhos dos profissionais da APS foi se modificando. $\mathrm{O}$ ver e o escutar diversas interaçóes ampliou minha perspectiva ao desfocar a atenção à dicotomia (visibilidade ou invisibilidade) para me aproximar do processo dinâmico da (in)visibilização, não linear, a ser compreendido na sua complexidade.

O (não)reconhecimento do usuário-trabalhador e das demandas de saúde relacionadas ao trabalho dava-se como o aparecer-desaparecer dos sinais intermitentes dos vagalumes aos olhos do espectador, a depender do "lugar" onde estivesse posicionado ${ }^{14}$. Uma visibilidade manifesta em diferentes gradientes e interrompida por circunstâncias que funcionavam como barreiras moduladoras do processo da abordagem do usuário-trabalhador pelo profissional e, indiretamente, outras que comprometiam, ofuscavam ou impediam tal reconhecimento.

A visibilidade límpida do usuário-trabalhador foi reconhecida nas circunstâncias em que o próprio usuário trouxe demanda de saúde qualificada e quando disparadores ativaram o interesse do profissional por saber: você trabalha? O que faz? Há quanto tempo? Tentou se aposentar? Porém, ainda que visibilizado na cena do atendimento, as condutas adotadas demonstravam que a visibilidade também se mostrava borrada, ofuscada ou mesmo invisível, como se uma lente opaca atrapalhasse o raciocínio clínico.

A invisibilidade do usuário-trabalhador aos olhos dos profissionais da USF foi considerada nos atendimentos em que o tema trabalho não foi mencionado; quando a informação fornecida em resposta à pergunta "você trabalha?" causava silêncio do profissional ou não repercutia em nenhuma abordagem específica; e quando o tema trabalho era trazido pelo usuário, não sendo explorado pelo profissional. 


\section{Quem é o usuário-trabalhador e quais as suas demandas de saúde: a percepção de profissionais da USF}

A resposta às questôes "fale sobre o perfil dos adultos atendidos por você"; "Que demandas de saúde normalmente apresentam?" revelou, em um primeiro momento, que os profissionais da USF faziam distinção entre o "usuário adulto" e o "usuário-trabalhador", como se pertencessem a categorias distintas.

[...] você deixa de ser uma coisa [adulto hipertenso, diabético] e vira uma outra [trabalhador]. Depois você passa a ser uma e não é mais a outra. (ProfTO1, entrevista)

O usuário adulto, portador de doenças crônicas, encontrado no domićlíio e acompanhado rotineiramente pela equipe: "Muitos hipertensos e diabéticos!". (ACS1, entrevista). E o usuário-trabalhador, que procurava o serviço por problemas agudos de saúde, sofria de dor, era visto pontualmente, de difícil vinculação para cuidado longitudinal.

[...] dor lombar relacionada a motociclistas, dor no corpo relacionada a trabalho como ajudante de pedreiro e até pedreiro. (ProfE1, entrevista)

Ser mulher, idoso(a), desempregado(a), hipertenso(a), diabético(a) e/ou estar com dor foram condiçôes propícias ao contato e maior proximidade do usuário com a USF. Por outro lado, trabalhar e ser homem representavam maior distanciamento, podendo implicar desassistência ou descontinuidade do cuidado.

[...] tenho mais acesso às mulheres, porque na maior parte os homens trabalham [...]. (ACS2, entrevista)

[...] adultos trabalham e nem todos a gente encontra em casa [...] Homem é mais difícil de lidar, porque não querem ir para médico. (ACS3, entrevista)

Essa compreensão dicotômica sobre a condição do usuário ficou mais evidente na fala do profissional de enfermagem, constituindo-se um guia importante para observaçôes e interaçốes no curso da pesquisa.

Muitas vezes o usuário não é visto como um trabalhador. [...] será avaliado pela queixa. Dificilmente a gente pergunta: você trabalha? Alguma situação, diante do relato do usuário, pode despertar para atividade de trabalho dele. [...] A costureira vem para o posto porque está com dor. Não importa se é costureira, o problema é que está com dor. As associações não são feitas. [...] É mais a queixa! Queixa-conduta. (ProfE2, entrevista) 
O relato ratificou uma tendência à abordagem "queixa-conduta" e trouxe uma pista: existem situações que fazem o profissional despertar para o trabalho do usuário. Segui minha observação e análise buscando encontrar que situaçóes seriam essas, identificando circunstâncias que davam visibilidade para o usuário-trabalhador no ato da interação com o profissional de saúde (Figura 1). Trata-se de disparadores para as perguntas: você trabalha? O que faz? Há quanto tempo? Tentou se aposentar?

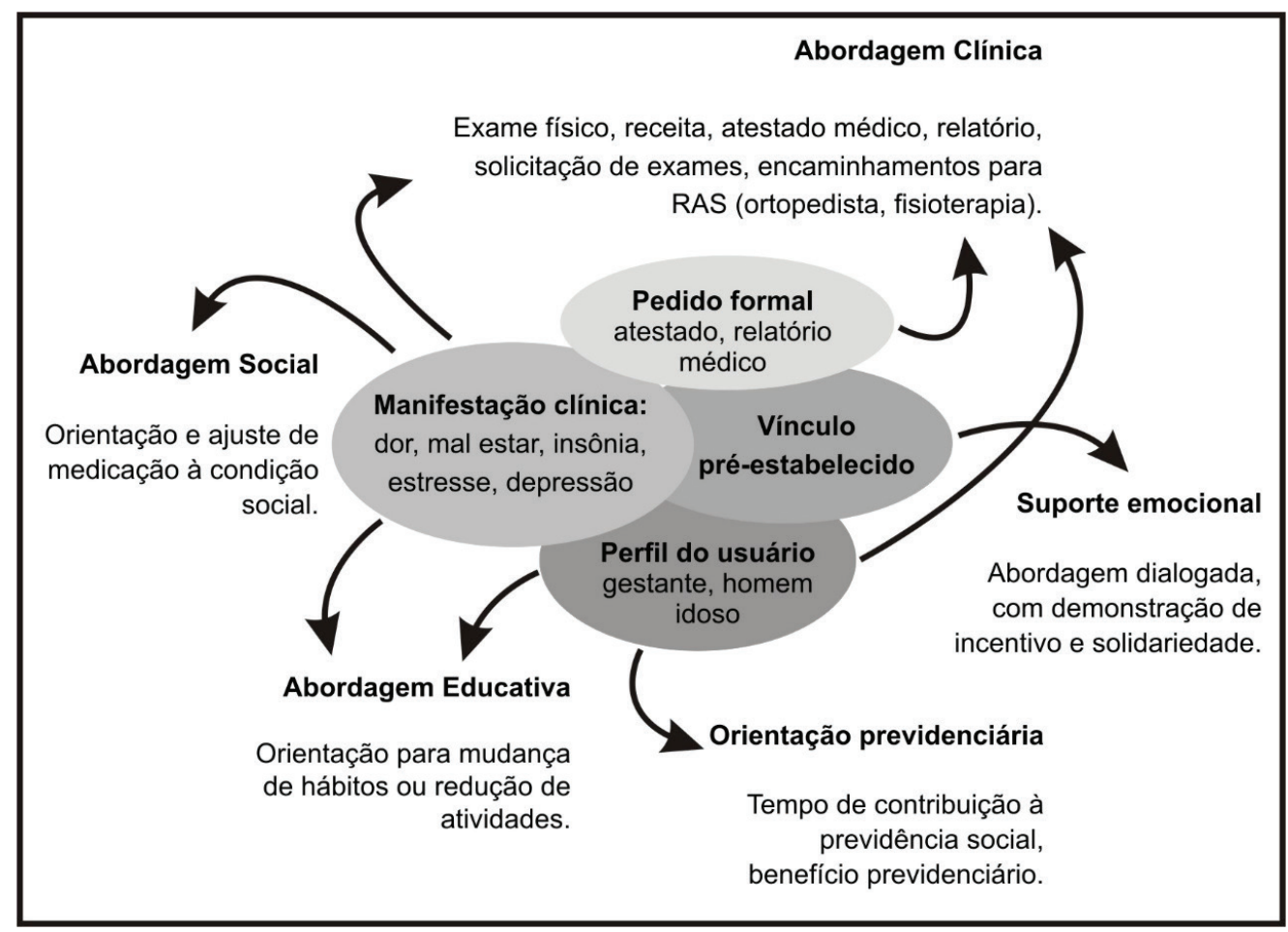

Figura 1. Disparadores para o reconhecimento do usuário-trabalhador Fonte: Elaboração própria

Os disparadores identificados produziam como ato seguinte o aparecimento do usuário-trabalhador diante do profissional de saúde, desencadeando condutas clínicas (exame físico, atestado médico, solicitação de exames, encaminhamento para especialistas, prescrição medicamentosa), educativas (adequação postural, de rotina e carga de trabalho), social (adequação da prescrição/orientação à condição de vida); apoio emocional (empatia e solidariedade) e/ou orientação previdenciária (tempo de contribuição, aposentadoria).

\section{A (in)visibilização do usuário-trabalhador nos espaços de interação da USF: percepções materializadas em realidades cênicas}

A pergunta disparadora “o que te trouxe aqui hoje?”, trazia à cena o(s) motivos(s) para procurar o serviço, abrindo possibilidades para o aparecer do usuário-trabalhador. Porém, a análise das observaçôes registradas revelou uma diversidade de demandas de saúde (Figura 2) que extrapolavam a capacidade de resposta dos profissionais da USF. 


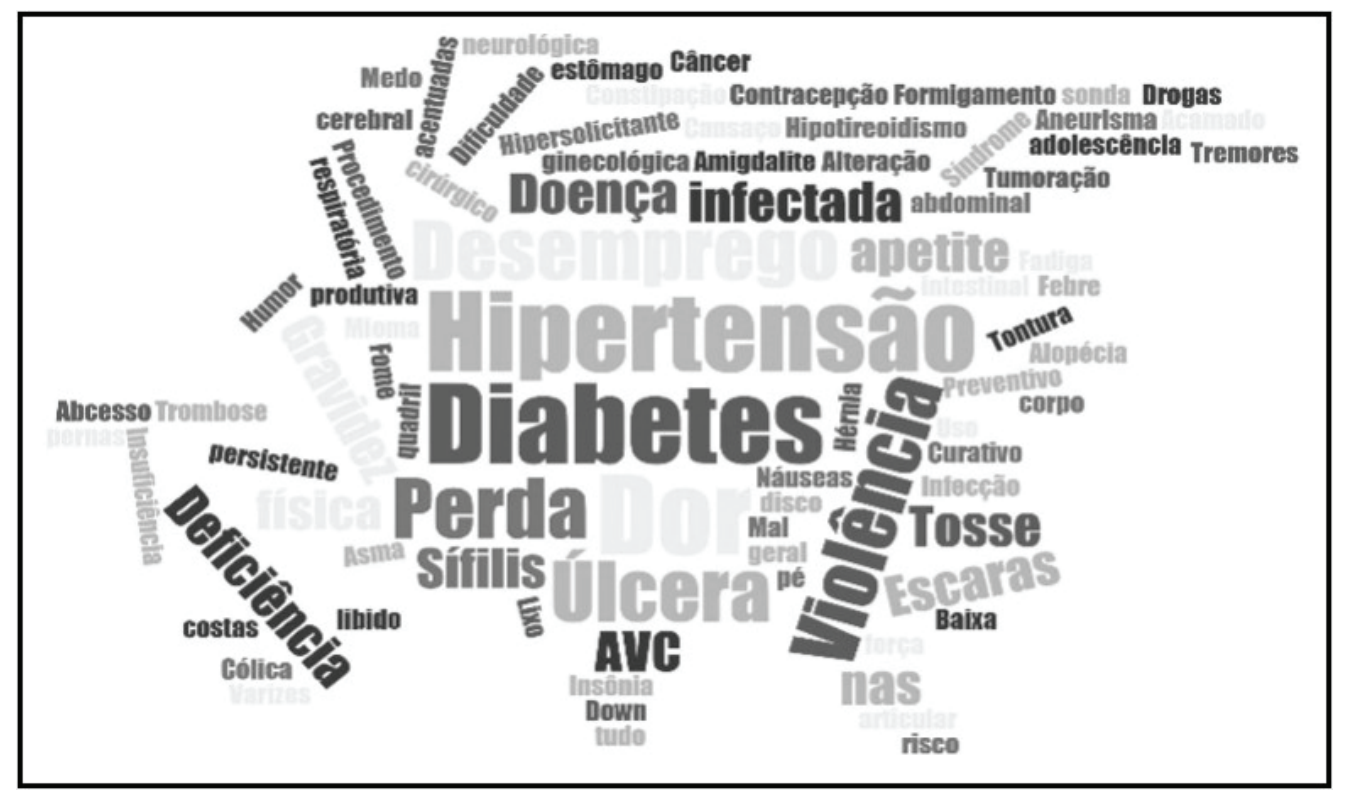

Figura 2. Representação da diversidade de demandas do usuário adulto atendidas nos espaços do acolhimento e consulta agendada.

Fonte: Elaboração própria

Uma triste realidade confrontava os profissionais com a necessidade de acolher e dar respostas rápidas e efetivas. Os pedidos formulados requeriam escuta sensível e qualificada; conhecimento técnico abrangente; habilidade para lidar com múltiplas e complexas demandas; conhecimento da RAS; retaguarda técnica especializada; recursos materiais; ambiência favorável e um mix de ofertas nem sempre disponível. O cotidiano de trabalho revelou, também, uma RAS não articulada e uma realidade adversa ao cuidado integral do usuário-trabalhador proposto pela PNSTT ${ }^{1,2}$.

Jonatas transformou a sua necessidade, não programada, em demanda espontânea e fez a relação da dor com o carregamento do botijão de gás. Prontamente, colocou o usuário-trabalhador visível aos olhos da médica. Sua demanda foi acolhida e reconhecida como legítima; as condutas adotadas faziam parte do "pacote de ofertas" ao alcance da médica: atestado médico, analgesia, encaminhamento e orientações.

Apesar de insuficiente para disparar a RAS na busca pela integralidade do cuidado na perspectiva da saúde do trabalhador, revelou caminhos percorridos e possibilidades de intervenção pelo profissional diante dos recursos disponíveis no contexto de trabalho na USF. No atendimento de trabalhador autônomo, o ProfM1 demonstrou que seu leque de ofertas era ainda mais limitado perante o dilema de tratar sem comprometer a renda: “(...) eu encaminhei para fisioterapia e recomendei exercícios de alongamento, não ficar horas seguidas trabalhando porque podia piorar a dor. Basicamente isso!”. 
A presença de dor na fala dos usuários adultos disparava a pergunta "você trabalha?", dando luz para o usuário-trabalhador na cena do atendimento. Ao contrário do que imaginava, a motivação para essa pergunta não era, necessariamente, para investigar a relação causal entre a dor e o trabalho.

Sempre pergunto se trabalha para ver se pode comprar medicação. [...] muitas vezes a gente é obrigado a prescrever a medicação que não é ideal para o paciente e tento adaptar com medicação disponível na USF. (ProfM1, entrevista)

As condutas eram guiadas por um raciocínio prático contextualizado, construído diariamente, fruto da "capacidade reflexiva"15 (p. 11) do profissional. Conhecia o perfil socioeconômico da população atendida e a realidade de dispensação de medicação na USF e, por isso, precisava saber se o usuário teria condições de comprar a medicação mais adequada para o seu tratamento.

Maria, cozinheira, não adscrita à USF, demandou curativo de úlcera infectada no tornozelo e renovação do atestado médico. “(...) trabalha como cozinheira e está com úlcera infectada, sem condiçôes de retornar ao trabalho. Precisa passar pela médica do acolhimento para pegar mais dias de afastamento.” (ProfE2, DC).

A usuária narrou sobre a evolução das "manchinhas vermelhas e carocinhos pelas pernas (...)" até virar uma "feridinha" que infeccionou. Enquanto ouvia, ProfE2 manteve-se preenchendo a ficha de atendimento de cabeça baixa. Repentinamente, levantou-se da cadeira e pediu-lhe para mostrar as pernas. Olhou atentamente por alguns segundos e falou: "existe uma doença sexualmente transmissível chamada sífilis que tem sintomas parecidos com esses (...) [prosseguiu constrangida] é uma doença tratável que tem cura. Podemos fazer o teste rápido e o resultado sai em 15 minutos”.

Um silêncio constrangedor reinou no consultório: o meu, ocultava uma série de indagaçóes diante de uma cozinheira com úlcera infectada e, também, daquela abordagem inesperada; Maria aparentava surpresa e incompreensão; ProfE2 manteve-se registrando as informaçóes na ficha de atendimento. $\mathrm{O}$ teste rápido foi realizado e o resultado foi reagente. Maria foi orientada quanto ao tratamento, conduzida para sala de procedimentos para depois passar pela médica.

A úlcera não foi ocasionada pelo trabalho de Maria, mas esse contribuía para agravá-la - "Quando fico muito em pé fica doendo e inchado. (...) a ferida fica minando, deixando a atadura ensopada.”. Em conversa na sala de espera, uma série de demandas relacionadas ao trabalho foram reveladas, para além do afastamento do trabalho.

Esse atendimento trouxe à cena a alternância aparecer/desaparecer de uma usuária-trabalhadora nas perspectivas do meu olhar especializado em ST e do olhar clínico qualificado do ProfE da USF. O olhar do profissional enxergou o que para mim não estava visível, a tempo em que ofuscou a sua visão para as demandas relacionadas ao trabalho e às questóes de ordem sanitária (cozinheira com úlcera infectada!). As condutas realizadas, ainda que resolutivas, não dispararam uma intervenção sanitária nem integração da USF com a Vigilância à Saúde. 
Ao atender uma paciente com gestação avançada, pernas edemaciadas, sem outras queixas ou sinais de gravidade, o ProfM1 perguntou se ela trabalhava e o que fazia. Ao saber que era vendedora em uma loja no shopping, forneceu atestado médico e orientou que conversasse "amigavelmente com os patrões para ver se poderia ter momentos de descanso.”. Para além do cuidado ofertado à gestante, aquela usuária-trabalhadora foi reconhecida e condutas foram adotadas no sentido de minimizar o efeito contribuinte ou agravante do trabalho em pé por longas horas.

Os limites da intervenção foram reconhecidos - "Foi o máximo que eu consegui fazer porque sei que a rotina de trabalho em shopping é pesada, é puxada, (...). Às vezes dou conselhos, mas não passa disso". (ProfM1, entrevista). Apesar de realizarem orientaçốes sobre cuidados para prevenção de agravos e proteção à saúde, percebi um sentimento de menor importância e, até mesmo, de impotência diante das demandas de saúde do trabalhador - "Foi o máximo que consegui fazer". (ProfM1, entrevista).

No caso de homens aparentando meia-idade, ao tempo em que o usuário-trabalhador aparecia na cena, as razões por trás da pergunta terminavam por ofuscá-lo. Preocupava-se com a condição financeira do usuário, indagando sobre sua situação previdenciária: Contribuiu para o INSS? Por quanto tempo? Tentou se aposentar?

Como um ato de solidariedade, o profissional passava informaçôes chegando a sugerir estratégias e fazer simulaçóes no momento da consulta: "Só tem 11 anos e seis meses de carteira assinada. Por que não continua recolhendo como autônomo para completar 15 anos de contribuição e poder se aposentar aos 65 anos?”. (ProfM2, DC). Uma forma de demonstrar possibilidades de o usuário se manter e sobreviver sem emprego, já que apresentava limitações para trabalhar e, na compreensão do profissional, esse seria o único recurso disponível.

À época da pesquisa, a questão da aposentadoria causava alvoroço na população brasileira diante das tentativas de consumação da reforma da previdência social. Certamente, o impacto da reforma estava sendo sentido pelos "profissionais da ponta", demonstrando a "sensibilidade" da APS às oscilações do contexto macroeconômico, político e social do país. Alguns sinais da diversificação do público que frequenta a USF foram observados: homens que passaram a buscar a unidade pela primeira vez, usuários que perderam o plano de saúde e buscaram assegurar o cuidado no SUS, notadamente desempregados e desprovidos de proteção social.

Percebi que as equipes estavam preparadas para identificar doenças e agravos que afetam a saúde dos usuários-trabalhadores ${ }^{2}$, mas ainda distantes de desenvolver ações eficazes e efetivas em tempo hábil. A integração assistência-vigilância é ainda uma imagem, um objetivo distante de ser alcançado.

Usuários-trabalhadores desempregados, uma triste realidade constatada nas falas dos profissionais: "vejo mais desemprego do que trabalho. (...) trabalhadores na maioria adoecendo pela falta de emprego, muita gente com depressão.” (ACS3, entrevista). Porém, ao mesmo tempo em que a relação saúde e desemprego se mostrava visível, era facilmente invisibilizada. O impacto do desemprego quando há quadro de incapacidade para o trabalho torna a condição de vulnerabilidade, sofrimento e adoecimento ainda mais complexa, o que também invisibiliza o usuário como um trabalhador. 
Simone aparentava pouco mais de quarenta anos, hipertensa e diabética. Chegou ao acolhimento com queixa de cefaleia frequente, notadamente fim de tarde. Adscrita à área daquele ProfM2, logo percebi o vínculo entre eles. A conversa fluiu facilmente, inicialmente guiada pela queixa de dor e solicitação de prescrição de ressonância magnética da coluna, alegando ter hérnia de disco lombar, com dor irradiada. Estava em acompanhamento com fisioterapeuta do Nasf-AB e se queixava por não conseguir marcar ortopedista no SUS, "no sistema nunca tem vaga disponível".

Ela revelou "dificuldade para dormir". "Você está estressada?", perguntou o profissional. "Estou desempregada e preocupada com minha saúde." (DC). Simone associou sua demanda com o desemprego, despertando sentimento de solidariedade do profissional "(...) quando você arranjar um emprego isso tudo melhora.”.

Simone falou sobre seu último trabalho, como camareira e que, depois da demissão, recorreu ao INSS, sindicato, advogado por conta de processo trabalhista, o que "não deu em nada”. Para ela, não tem mais condição de trabalhar por conta das dores. Para o profissional, “(...) o problema do povo é esse, social.”. Disse que tem “dor e não pode fazer nada [trabalhar]. Qual empresário vai dar um emprego para ela?”. Assim, a condição de incapacidade para o trabalho de Simone revelou-se como resultado de um desarranjo entre os diferentes sistemas: pessoal, de saúde, organizacional e de compensação ${ }^{16}$.

A falta de perspectiva de resolver o "problema social" de Simone contribuiu para a invisibilização da sua condição de usuária-trabalhadora, desempregada, que sofre de dor e insônia, sendo as condutas orientadas para marcação de consulta com fisioterapeuta e com ortopedista - "Agora você tem dois caminhos: operar ou fazer fisioterapia." (ProfM2, DC). Esse atendimento, ao tempo em que invisibilizou a trabalhadora, deu maior visibilidade aos limites das intervenções no contexto da USF e indícios da falta de incorporação da atuação em rede.

Aos poucos, a invisibilidade do usuário-trabalhador foi demonstrando que a USF tem se constituído como uma porta de entrada sem saída ${ }^{17}$, que não consegue atuar na perspectiva da determinação social da saúde (DSS), que absorve e reprime demandas de ST em uma rede cujos pontos não se comunicam. Se por um lado demonstra limites desse equipamento da APS, aponta para possível "gargalo no acesso aos níveis mais complexos do sistema, a exames e clínicas especializados” (p.2068) ${ }^{18}$ e fragilidades na RAS.

O atendimento de João, 62 anos, ratificou essa compreensão e demonstrou lacunas na coordenação do cuidado à saúde do trabalhador pela USF. Atendido pela primeira vez na USF por conta de pico hipertensivo, justificou que não tem feito acompanhamento médico por "causa do trabalho". Aquela fala soou como uma sirene de alerta - trabalho, que trabalho? Mas o profissional continuou a anamnese clínica guiado pelo pedido: "verificar pressão arterial (PA) e atualizar receita vencida." (DC).

Durante exame físico, João deu outras pistas que poderiam ter sido exploradas. Puxou o braço bruscamente no momento da aferição da PA: "esse braço aqui não, porque sofri um acidente." Um acidente de trabalho (pensei)? A aferição prosseguiu sem nenhum comentário a respeito, mas seus olhos vermelhos chamaram a atenção do profissional - “estão sempre assim? Já foi a um oftalmologista?”. Para mim, aquela manifestação clínica foi mais uma pista que poderia ter sido investigada. 
Aproveitei que o profissional foi demandado por duas estudantes de medicina do internato e perguntei: "o senhor trabalha?". Ele, prontamente, respondeu "sou pintor e pedreiro.”. O profissional, ainda com as estudantes no consultório, virou-se dizendo: "Esses olhos vermelhos devem ser por causa disso [do trabalho].” (ProfM2, DC). O atendimento foi finalizado sem mais perguntas nem orientações acerca do trabalho de João. O profissional realizou ajustes nas medicaçôes, solicitou exames de laboratório e o orientou a marcar consulta com oftalmologista.

Minha interferência deu visibilidade ao usuário-trabalhador, pintor e pedreiro, que foi reconhecido pelo médico ao significar a vermelhidão dos olhos de João com as atividades de trabalho. Como conduta, recomendou consulta com oftalmologista, não tendo sido realizadas orientações quanto à proteção adequada, nem relatório de encaminhamento ou ficha de referência relatando possível relação com o trabalho para o médico especialista.

Ao tempo em que os limites para coordenação do cuidado do usuário na RAS foram sendo revelados - "Não damos conta, a gente é Atenção Básica e nossa rede está totalmente fragilizada." (ProfM2, DC) -, verifiquei que havia um desconhecimento sobre o papel do Centro de Referência em Saúde do Trabalhador (Cerest): "Nunca tivemos reunião com o Cerest para discutir caso, nunca se apresentaram para a unidade. É uma coisa distante, apesar de achar que é nossa referência, que podemos ligar e está na rede...” (ProfE1, entrevista).

A RAS, como estratégia para superar a fragmentação da atenção e da gestão nas Regiôes de Saúde e aperfeiçoar o funcionamento político-institucional do SUS, visa assegurar efetividade e eficiência nas açôes e nos serviços prestados ao usuário. Nessa perspectiva, a USF seria o centro de comunicação ou "nó intercambiador no qual se coordenam os fluxos e contrafluxos do sistema de Atenção à Saúde” (p. 2301) ${ }^{19}$.

Considerando a responsabilidade sanitária da USF, deveriam ser produzidas informaçốes sobre "atividades produtivas, perfil epidemiológico e situaçôes de vulnerabilidade da população e sua incorporação no planejamento das ações”20 (p. 31). Porém, o trabalho real das eSF dessa USF revelou adversidades que comprometiam a produção de informações de saúde e, consequentemente, a coordenação do cuidado do usuário-trabalhador no SUS.

Por outro lado, o distanciamento do Cerest demonstra que essa instância não tem se constituído como suporte técnico, propagação da cultura do trabalho como DSS e disparador de ações intra e intersetoriais no território de sua abrangência ${ }^{21}$.

Cheguei àquela USF com um olhar de fora e de longe, impregnado por ideias preconcebidas acerca da invisibilidade do trabalhador na APS, mas a aproximação etnográfica possibilitou-me viver o objeto de investigação, ampliando minha visão por meio de um olhar de perto e de dentro da USF.

Aos meus olhos, trabalhadores formais, informais, autônomos, aposentados e desempregados fizeram-se visíveis. Para os profissionais, essa visibilidade (não)resultou em condutas; pareceu não fazer sentido ou mesmo não foi possibilitada. Assim, importante ressaltar que a análise do processo de (in)visibilização do usuário-trabalhador na USF se deu por meio do meu olhar, orientado pela experiência e formação no campo da saúde do trabalhador. 
A visibilidade do usuário-trabalhador esteve comprometida em diferentes gradientes que dificultaram, atrapalharam ou mesmo impediram o reconhecimento de demandas relacionadas ao (não)trabalho. As interações estabelecidas possibilitaram descortinar aspectos imbricados resultando na (in)visibilidade do usuário-trabalhador, esquematicamente separados em camadas (Figura 3), sem perder de vista a complexa e dinâmica interação entre eles.

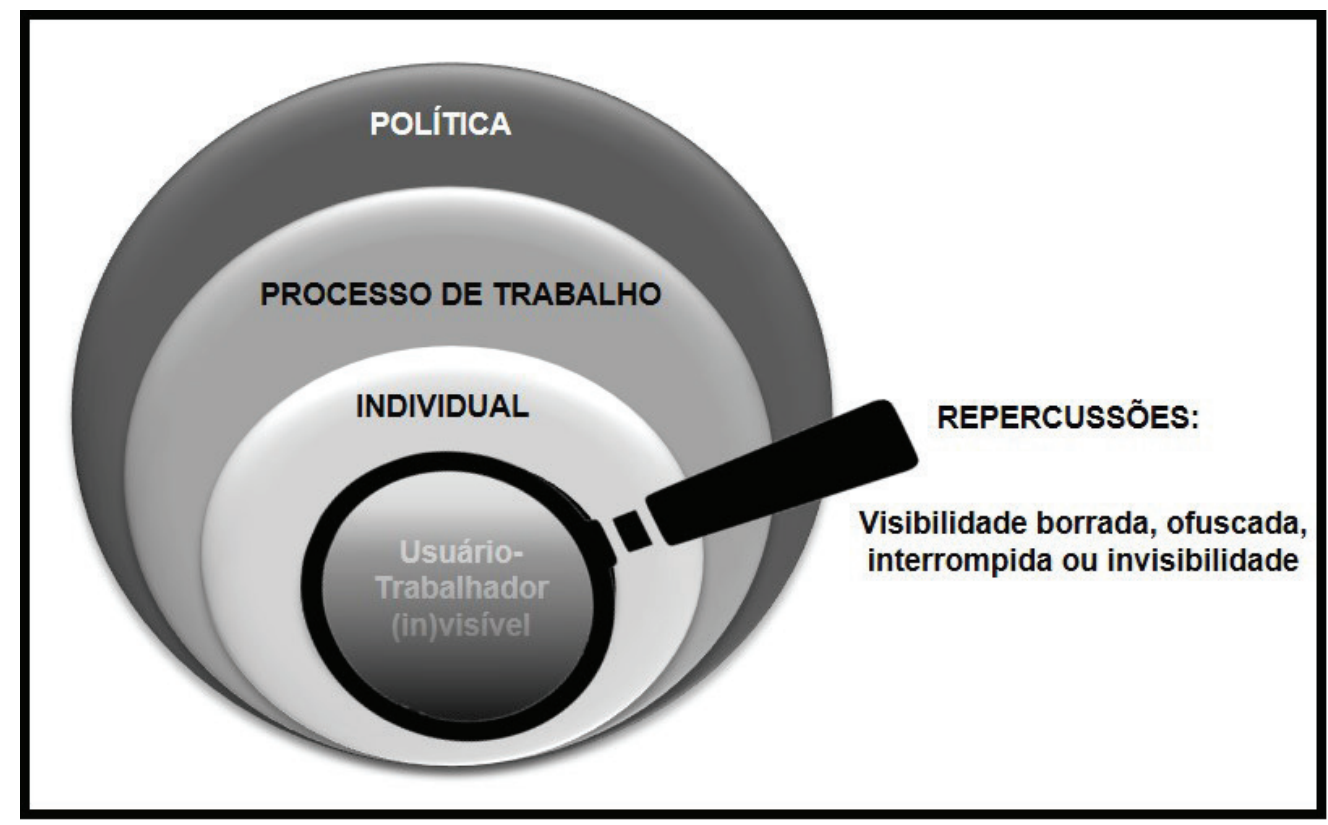

Figura 3. Representação das barreiras para o reconhecimento do usuário-trabalhador Fonte: Elaboração própria

Permeando a interação do usuário adulto com o profissional estavam: singularidades de vida, características sociodemográficas do território, condições de trabalho, modelo de gestão adotado, contexto político-econômico. Assim as camadas foram definidas no processo analítico, visando representar a (in)visibilidade como resultado das interrelaçôes entre as expectativas dos usuários e as competências dos profissionais de saúde (Individual), as condições dos processos de trabalho dos profissionais (Trabalho Real), as decisôes políticas e administrativas do momento (Política).

As interações entre usuários e profissionais estiveram mediadas por expectativas, pedidos, anseios e sensaçôes. De um lado, o usuário-trabalhador trazia demanda de saúde embebida de expectativas pelo atendimento, anseios e descontentamentos. Do outro, o profissional-trabalhador, guiado pelo conhecimento técnico e prático, pela vocação e pelo desafio do cuidado, fragilizado pela violência do território e exaustivamente requerido. Geralmente, nenhum deles se percebia como trabalhador.

A formação biomédica tende a direcionar o foco do profissional para queixa comprometendo a visibilidade do usuário como um trabalhador ${ }^{20}$, comprometendo a oferta de suporte mais eficiente perante as múltiplas dimensóes dos problemas de saúde dos usuários atendidos ${ }^{22}$. Centra-se no "fármaco" como oferta em troca do diagnóstico 
realizado para que a saúde seja possibilitada ${ }^{23}$. Aos olhos dos profissionais, esse parecia ser o recurso mais próximo ao seu alcance, restando-lhe, em meio ao silêncio posto ou à redução do diagnóstico a uma nosologia biomédica, "sustentar as condiçôes de produção de um atendimento queixa-conduta”23 (p. 10).

Aspectos do trabalho na USF e sua relação com o objeto de interesse do estudo demonstraram que a forma como o processo de trabalho dos profissionais estava organizada contribuía para a (in)visibilização do usuário-trabalhador e suas demandas de saúde relacionadas ao trabalho ${ }^{24}$. Um cotidiano de trabalho marcado pela pressão de tempo imposta por número de atendimento por turno de trabalho; processo de remapeamento do território, com ampliação da área de cobertura e perda de vínculos estabelecidos; lidar com dramas da população sem suporte emocional nem condiçóes satisfatórias para atendê-la; acuados pela violência do território que adentrava a USF; atendimentos constantemente interrompidos; escassez de recursos materiais e insumos.

O trabalho dos profissionais se dava em condiçóes que concorriam e limitavam o "pacote de ofertas" para atender a demandas de saúde dos usuários. Um contexto de trabalho caracterizado por incertezas que demandam esforço e habilidade dos profissionais para solucionar problemas imprevisíveis ${ }^{25}$, impossibilitando o levantamento de informaçôes acerca do trabalho do usuário: "o que faz? Como faz? Que produtos e instrumentos utiliza? Em que condiçóes executa o trabalho? Há quanto tempo? Em que ritmo? Quais as exigências de produtividade?”20 (p. 32).

Como pano de fundo da intensificação do trabalho, identifiquei decisões e artifícios que comprometiam a efetivação da APS integral no contexto brasileiro. A aprovação da Política Nacional de Atenção Básica (PNAB), com revisão de diretrizes para organização da Atenção Básica no âmbito do SUS, trouxe possibilidades para que os gestores municipais decidissem pela ampliação da cobertura da APS por meio da descaracterização da ESF5. Uma proposta de reorganização desse sistema por meio da implementação da APS, "assumida pelo governo brasileiro" ${ }^{26}$ (p. 163), às custas do suor, do desgaste físico e mental e do adoecimento dos trabalhadores de saúde, repercutia como um efeito em cascata nos âmbitos municipal e local da USF. A exemplo da mudança na delimitação das microáreas de atuação das eSF privilegiando o aumento de indivíduos cadastrados em detrimento da qualidade da assistência prestada.

Assim, a (in)visibilidade do usuário-trabalhador revelou-se em meio a distorçôes que tendem a reforçar uma atuação baseada na abordagem queixa-conduta em detrimento da atuação baseada nos determinantes e condicionantes dos agravos à saúde relacionados ao trabalho ${ }^{5}$, comprometendo o cuidado integral do usuário-trabalhador no SUS. Desafios esses que precisam ser pautados para orientar a integração efetiva das açốes de Vigilância em Saúde do Trabalhador na APS. 


\section{Conclusão}

Os resultados deste estudo apontam a diversidade de aspectos imbricados na (in)visibilidade do usuário-trabalhador na interação com os profissionais de saúde, processo dinâmico acionado por alguns disparadores na clínica na APS. Por trás desse processo, vários aspectos se manifestam, dispostos em diferentes camadas, que apontam limites e possibilidades do reconhecimento e da ação sobre a ST, que transcendem a formação do profissional de saúde.

Os disparadores que deram luz à pauta "trabalho" durante os atendimentos foram: pedido formal qualificado, queixa de dor, estar gestante, ser homem de meia-idade. Porém, a visibilidade foi sustentada de forma frágil, pela possibilidade de o profissional se reconhecer capaz e/ou dispor de recursos para atendimento da demanda de saúde sustentados pelo tripé: certificação da doença/incapacidade; condições financeiras (adesão ao tratamento) e orientações (de saúde e previdenciárias).

A invisibilidade do usuário-trabalhador na APS demonstra lacunas em mão dupla entre a ST e a APS. Como resultado de vazios não preenchidos pelo campo da saúde do trabalhador, há necessidade de investimentos que impulsionem um protagonismo da área técnica especializada na delimitação de açôes articuladas e de matriciamento das equipes da APS, ampliando, assim, o leque de ofertas para o cuidado integral à saúde do usuário-trabalhador.

\section{Filiação \\ (e) Departamento de Medicina Preventiva e Social, Faculdade de Medicina da Bahia, Universidade Federal da Bahia. Salvador, BA, Brasil.}

\section{Contribuições dos autores}

Andréa Garboggini Melo Andrade participou da produção dos dados empíricos. Andréa Garboggini Melo Andrade, Robson da Fonseca Neves e Mônica Angelim Gomes de Lima participaram da concepção do projeto, organização dos dados e da escrita inicial do manuscrito. Todos os autores participaram ativamente da discussão dos resultados, da revisão crítica do conteúdo e da aprovação da versão final do manuscrito.

\section{Financiamento}

Este artigo é um dos resultados da dissertação de mestrado do Programa de Pós-Graduação em Saúde, Ambiente e Trabalho da Universidade Federal da Bahia, pesquisa vinculada ao projeto de pesquisa-intervenção interinstitucional "Saúde do Trabalhador na Estratégia de Saúde da Família: compreender para agir” (PPSUS, edital 003/2017), financiado pela Fundação de Apoio à Pesquisa do Estado da Bahia-Fapesb.

\section{Agradecimentos}

À Diretoria de Vigilância e Atenção à Saúde do Trabalhador (Divast), ao Centro de Referência em Saúde do Trabalhador de Salvador (Cerest Salvador), à Universidade Federal da Bahia (Ufba), à Fundação de Apoio à Pesquisa do Estado da Bahia (Fapesb), aos profissionais de saúde e usuários-trabalhadores que, gentilmente, aceitaram participar deste projeto. 


\section{Conflito de interesse}

Os autores não têm conflito de interesse a declarar.

\section{Direitos autorais}

Este artigo está licenciado sob a Licença Internacional Creative Commons 4.0, tipo BY (https://creativecommons.org/licenses/by/4.0/deed.pt_BR).

\section{(cc) BY}

Editora

Denise Martin

Editora associada

Maria Dionísia do Amaral Dias

\section{Submetido em}

$22 / 10 / 20$

Aprovado em

$30 / 04 / 21$

\section{Referências}

1. Brasil. Ministério da Saúde. Portaria no 1.823, de 23 de Agosto de 2012. Institui a Política Nacional de Saúde do Trabalhador e da Trabalhadora. Brasília: Ministério da Saúde; 2012.

2. Brasil. Ministério da Saúde. Saúde do trabalhador e da trabalhadora. Brasília: Ministério da Saúde; 2018. (Cadernos de Atenção Básica, n. 41).

3. Silva MVS, Miranda GBN, Andrade MA. Sentidos atribuídos à integralidade: entre o que é preconizado e vivido na equipe multidisciplinar. Interface (Botucatu). 2017; 21(62):589-99.

4. Lacerda e Silva T, Dias EC, Pessoa VM, Fernandes LDMM, Gomes EM. Saúde do trabalhador na Atenção Primária: percepções e práticas de equipes de Saúde da Família. Interface (Botucatu). 2014; 18(49):273-88.

5. Dias E, Silva T, Almeida M. Desafios para a construção cotidiana da Vigilância em Saúde Ambiental e em Saúde do Trabalhador na Atenção Primária à Saúde. Cad Saude Colet. 2012; 20(1):15-24.

6. Morosini MVGC, Fonseca AF, Lima LD. Política Nacional de Atenção Básica 2017: retrocessos e riscos para o Sistema Único de Saúde. Saude Debate. 2018; 42(116):11-24.

7. Fraser N. A justiça social na globalização: redistribuição, reconhecimento e participação. Rev Crit Cienc Sociais. 2002; 63:7-20.

8. Laplantine F. A descrição etnográfica. São Paulo: Terceira Margem; 2004.

9. Oliveira RC. O trabalho do antropólogo. 2a ed. Brasília, São Paulo: Paralelo 15, Unesp; 2006.

10. Pires AP. Amostragem e pesquisa qualitativa: ensaio teórico e metodológico In: Nasser AC, tradutor. A pesquisa qualitativa: enfoques epistemológicos e metodológicos. $4 \mathrm{a}$ ed. Petrópolis: Vozes; 2014. p. 154-210. 
11. Campos GWS. Saúde mental e atenção primária: apoio matricial e núcleos de apoio à saúde da família. In: Nunes M, Landim FLP, organizadores. Saúde mental na atenção básica: política e cotidiano. Salvador: EDUFBA; 2016. p. 29-46.

12. Gergen KJ. O movimento do construcionismo social na psicologia moderna. Rev Int Interdiscip INTERthesis. 2009; 6(1):299-325.

13. Schiffler ACR, Abrahão AL. Interferindo nos microprocessos de cuidar em saúde mental. In: Gomes APC, Merhy EE, organizadores. Pesquisadores IN-MUNDO - Um estudo da produção do acesso e barreira em saúde mental. Porto Alegre: Rede UNIDA; 2014. p. 89-103.

14. Didi-Huberman G. Sobrevivência dos vaga-lumes. Belo Horizonte: UFMG; 2011.

15. Garfinkel H. Estudos de etnometodologia. Petropolis: Vozes; 2018.

16. Loisel P, Anema JR. Handbook of work disability prevention and management. New York: Springer New York; 2013.

17. Dowbor TP. O Trabalho com Determinantes Sociais de Saúde no Programa de Saúde da Família no Município de São Paulo [tese]. São Paulo: Universidade de São Paulo; 2008.

18. Dias EC, Rigotto RM, Augusto LGDS, Cancio J, Hoefel MDGL. Saúde ambiental e saúde do trabalhador na atenção primária à saúde, no SUS: oportunidades e desafios. Cien Saude Colet. 2009; 14(6):2061-70.

19. Mendes EV. As redes de atenção à saúde health care networks. Cienc Saude Colet. 2010; 15(5):2297-305.

20. Dias EC, Lacerda e Silva T. Possibilidades e desafios para a atenção integral à saúde dos trabalhadores na atenção primária. Belo Horizonte: Coopmed; 2013. p. 22-41.

21. Dias EC, Hoefel MG. O desafio de implementar as açôes de saúde do trabalhador no SUS: a estratégia da RENAST. Cienc Saude Colet. 2005; 10(4):817-27.

22. Justo A. A humanização como diretriz reorganizativa da política e das práticas em saúde. Soc Debate. 2012; 16(1):139-54.

23. Sancho KA, Pfeiffer CRC, Corrêa CRS. Medicalização, diagnóstico clínico e queixaconduta - redes de significação em jogo. Interface (Botucatu). 2019; 23:1-13.

24. Dias MDDA. Compreender o trabalho na Atenção Primária à Saúde para desenvolver açóes em Saúde do Trabalhador : o caso de um município de médio porte. Rev Bras Saude Ocup. 2013; 38(127):69-80.

25. Shimizu HE, Carvalho Junior DA. O processo de trabalho na estratégia saúde da família e suas repercussốes no processo saúde-doença. Cienc Saude Colet. 2012; 17(9):2405-14.

26. Oliveira MAC, Pereira IC. Atributos essenciais da atenção Primária e a estratégia Saúde da família. Rev Bras Enferm. 2013; 66 Esp:158-64. 
This study aimed to understand how work-related health needs appear in the interaction between service users (workers) and family health professionals and affect care. We adopted ethnographic methods to collect data, including recording observed appointments in a field diary and situated and semi-structured interviewing. The worker became visible to the health professionals through formal requests, clinical manifestations, patient-professional bonds and the patient profile. During the appointments we observed responses oriented by clinical complaints and gaps in the coordination of care. The (in)visibility of workers in the context of appointments was articulated and in layers, encompassing aspects of the individual, the work process and social protection. Understanding these overlapping aspects in the delivery of care to workers in primary care settings can contribute to improving and broadening the resolvability of health care in the public health system.

Keywords: Worker. Workers' health. Primary health care. Integrality in health. Qualitative research.

Se buscó entender cómo las demandas de salud relacionadas al trabajo aparecen en la interacción usuario (trabajador) - profesionales de Salud de la Familia y repercuten sobre el cuidado. Se adoptó la perspectiva etnográfica para la producción de datos, con registro en diario de campo de las atenciones observadas, entrevistas situadas y semiestructuradas. El trabajador pasó a ser visible para los profesionales por medio de pedidos formales, manifestaciones clínicas, vínculo establecido y perfil del usuario. En las atenciones se observaron respuestas orientadas por la queja clínica y lagunas de coordinación del cuidado. La (in) visibilidad del trabajador en el contexto de las atenciones apareció articulada y en capas, alcanzando aspectos del individuo, proceso de trabajo y de la protección social. Comprender esas superposiciones en el cuidado a los trabajadores en la atención primaria puede contribuir para calificar y ampliar la capacidad de resolución de la atención de la salud en el Sistema Público de Salud.

Palabras clave: Trabajador. Salud del trabajador. Atención primaria de la salud. Integralidad en salud. Encuesta cualitativa. 